\title{
Writing the Self-at-War: World War I Popular Writings as "Technologies of the Self"
}

\author{
Federico Mazzini $^{1 *}$ \\ ${ }^{1}$ University of Padua, Italy \\ *Corresponding author: Federico Mazzini: federico.mazzini@unipd.it
}

\begin{abstract}
:
Based on the analysis of more than 150 diaries and memoirs, this article highlights the rhetorical strategies used to define the self and shape the idea of war that characterized a specific peasant community, the Italian-speaking soldiers from the Trentino region that fought for Austria-Hungary in World War I. Through this case study the essay discusses how the Foucauldian notion of "technology of the self" can be applied to the study of war testimonies and to the historiographical debate on the nature of World War I "war culture". By looking at the texts not in their message but in their form and in their function for the authors the study proposes a methodology to interpret sources that have been often deemed too repetitive and hermetic to be part of a systematic historical analysis.
\end{abstract} Writing the Self-at-War: World War I Popular Writings as "Technologies of the Self". Open Science Journal 2(4)

Received: $27^{\text {nd }}$ February 2017

Accepted: $1^{\text {st }}$ November 2017

Published: 23 $3^{\text {rd }}$ December 2017

Copyright:@ 2016 This is an open access article under the terms of the Creative Commons

Attribution License, which permits unrestricted use, distribution, and reproduction in any medium, provided the original author and source are credited.

Funding: The author(s) received no specific funding for this work

Competing Interests: The author have declared that no competing interests exists.

Keywords: War Culture, World War One, Popular Writing, War Violence

\section{Introduction}

It is widely known that the First World War caused a veritable "explosion" of popular writing. The experience of spatial dislocation together with the disconcerting novelty of the events, as well as a growing level of literacy throughout Europe, favoured the rise of an unprecedented and in many ways unique phenomenon: millions of men, from a variety of cultural and personal backgrounds, decided to write about the same macro-event. This harvest of 
writings has raised far from minor problems for historians. In recent years, and particularly in France, cultural historians have been increasingly prone to doubt the value of these texts as a means to unlock the "culture of war" [1]. In the course of the now two decade-long debate regarding the experience of the trenches - whose defining feature is seen by some as "violence from below" and by others as "coercion" - the meaningfulness of the original testimonies has been several times contested [2,3], and as many times vindicated [4]. For the first group of historians, for the most part gravitating around the Péronne international workshop, such sources express a "justificatory impulse" which deprives them of all value as mirrors of a reality at the front characterised by hatred of the enemy and by a "crusader spirit". If a soldier's mission is to kill, and if the Great War was the massacre we all agree it was, how is it possible to lend credence to witnesses who almost never admit to having perpetrated acts of violence? The first-person accounts we have, which are at once reticent and selfjustifying, have exercised a "dictatorship of testimony" over the historians and should now be outflanked by new sources and fresh interpretations.

For the second group of historians, such sources are an indispensable aid to historical understanding. They insist that every conclusion as regards the role of violence perpetrated must be rooted in the words uttered by the social actors: "Should we discount the testimonies from Auschwitz", Frédéric Rousseau asks himself rhetorically, "on the grounds that they are, for good reason and save for rare exceptions, testimonies that are at a distance, survivors' testimonies?" [5]

Despite his mistrust, Audouin-Rouzeau is still prepared to insert testimonies (well-educated, and therefore inevitably in a minority given the average literacy levels of the soldiers) when they evince hatred of the enemy and arguments regarding the "anthropological diversity" of the opposing armies. Conversely, even those who are most fervent in their claims for the validity of such testimoniesas sources have often used those authors or passages which more directly or frankly reflect their own "pacifist" positions as regards the experience of conflict, thus failing to address the question of how representative they are of the overall "culture of war" and, above all, furnishing no explanation for the reticence, indubitably real, which popular testimonies display towards the theme of acts of violence perpetrated in the first person and towards direct reflection upon the nature of war.

The choice would seem to be between a careful selection of authors who, on account of their education or through some error, fail to be reticent about violence and a willful disregarding of all such reticence, divesting it of all historical meaningfulness.

This essay shall try to identify a path that both avoids the "dictatorship of testimony" and does not entail jettisoning testimonies as sources, and which at the same time directly addresses the problem of their hermetic and lacunary nature. The first part of this essay will define the sources and the community that produced them, the Italian-speaking soldiers from Trentino that fought for Austria-Hungary during the First World War. Diaries and memoirs will be the object of a formal analysis, inspired by Hayden Whites' tropological theory, that will isolate the main topics and their hierarchization inside the single texts. The second part will argue that hermetic journals and personal should be read by historians not primarily as conveyors of a message but as a tool in the soldiers' hands: a Focauldian "technology of the self". The second part will look at the 
functions of this tool and at its role in reshaping the authors' war experience. The last part will look at how the tool was used in relation to war violence, and in conclusion it will discuss how the Trentine case and peasant writings in general can be significant for the debate over the culture of war and the experience of the trenches.

\section{Methodology adopted by the study}

This essay will argue in two different directions. On the one hand, it shall concentrate upon the modalities of emplotment that are characteristic of popular writing, taking its cue from Hayden White's historiographical analysis of texts by historians. By focusing the attention upon the modalities of correlation between events rather than upon what is actually said, the study hope to outflank the extreme selectivity of the sources and their natural reticence towards the narration of violence. The close comparison of analogous sources necessary to identify common modalities of emplotment has led to undertake an analysis of a group limited at once numerically, geographically and socially, namely Italianspeaking conscripts from the Trentino region in the Hapsburg Empire, for the most part of peasant origin. This analysis entails a return to sources which, though very familiar to historians who have considered Trentino at war, have rarely been subjected to historiographical analysis, on account of their seemingly limited meaningfulness and despite the fact that they represent the typology of the most widespread diaristic sources for the group in question. Such an analysis is especially rewarding if applied to authors of peasant origin, whose literacy is shaky at best and who display precious little mastery of "bourgeois" literary genres, or who, in other words, have narrative priorities of their own and at odds with "ours". The markedly peasant make-up of all the armies involved, with the exception of the British, suggests that an attempt of this kind might prove equally rewarding in other regional and national contexts, however much the ultimate findings will no doubt differ.

The second proposal of this study is to view writing as a tool in the soldiers' hands. Given the vertiginous spread of writing during the war we must assume that the lacunae are such only from the point of view of the historians: how is one to account for the spread of models of writing that are surprisingly analogous on the stylistic and thematic plane if not by acknowledging that these models fulfilled a function? Hence, one would ask if these "lacunae" and "distortions" might not be one of the keys to unlocking the nature of the experience of war for the group in question. Who, on the very day that he had for the first time killed a man, would choose to record the event in the same dry and impersonal tone with which he had previously compiled his lists of meals and maneuvers? Who, amongst our contemporaries, would choose to express their own experience of war, not through what was most surprising and unusual (violence, battle, artillery fire...), but through what was repetitive and monotonous (trench duties, meals consumed, troop movements)? Yet this is precisely what the great majority of the Trentine conscripts did. I discern in this hiatus between what happened (the conscripts killed even if they don't write it down) and what is recorded the proof that writing was a tool serving to tame reality and to render it more 
consistent with the requirements and expectations of the author. The study suggest, in other words, that we look at popular war writing in the light of what, in the last phase of his intellectual life, Michel Foucault called "technologies of the self". Foucault defined these as tools that allow individuals to perform "[...] a certain number of operations on their own bodies and souls, thoughts, conduct, and way of being, so as to transform themselves in order to attain a certain state of happiness, purity, wisdom, perfection, or immortality"[6]. It is well known that among the examples mentioned by Foucault in various works there are a variety of practices such as (religious or psychoanalytic) confession, physical exercise, the abstention from pleasure and different forms of personal writing. Among these latter, what is closest to my case study is probably the practice of the hupomnemata, a notebook of sorts characterized by a variety of themes which dates back to the first and second centuries $\mathrm{AD}$ and which aims not "to pursue the unspeakable, nor to reveal the hidden, nor to say the unsaid, but on the contrary to capture the already said, to collect what one has managed to hear or read, and for a purpose that is nothing less than the shaping of the self" [7].

The important differences between the practices analyzed by Foucault and popular war writing should not be underestimated, particularly the "voluntary" character of the technologies described by the French Philospher, which were marked by a wide intellectual theorization and often accompanied by considerations delineating their use, objectives and modalities with respect to the writer's subjectivity. While Foucault's technologies prescribe a conscious process of evolution of the self, personal war writing possesses an utterly spontaneous character.

A second difference is linked to the category of "transformation". The adoption of the Foucaldian technology is due to a desire for personal development; popular writing, a spontaneous mass phenomenon, originates from the urge to preserve the self from a transformation imposed by the total war and by the military apparatus. It is a tool that allows to place the self in the succession of events in a way that, though unnatural, is at least acceptable within a system of values created outside the context of the war and in which violence is condemned and the passage of time is measured through repeated and foreseeable actions. The aim of popular writing is the preservation of the self rather than its transformation.

These two objections do not put into question either the legitimacy or the relevance of Foucault's category in relation to this specific case study. In both cases, writing is a means through which the self acts upon itself in order to "improve" its present condition. In spite of a lack of theorization, the surprisingly widespread and more or less homogenous use of both rhetorical mechanisms and thematic choices in different authors shows the existence of a set of "functioning rules" that are no less rigid than those theorized in the Christian pastoral or in Stoic ethics.

The use of the Foucauldian category does, moreover, present indubitable advantages. First of all, this approach reaffirms the centrality of the self in the reading of memorialistic sources; the author of these was their first, and often their only reader. The communication begins and ends in the self: all the stylistic and thematic choices must be explained in terms of the author/recipient, rather than through the facts narrated. Diaries and memoirs are not only, or first and foremost, "sources" and cannot therefore be wholly "mute" or entirely 
meaningless. At the very least they speak in a clear and explicit fashion of a need, that of compiling such accounts, day by day, often in the most terrible circumstances, and this need calls for an explanation. The issue of the "reliability of the testimonies", which has been a key aspect of recent historiographical debate, somehow ceases to be significant: "one must consider these texts not as the mirror-image of a situation, but rather as the formulation of a need. This is precisely the reason why they belong to reality" [8]

But it is possible to go deeper still. The repetitive nature of the modalities of emplotment and of the stylistic and thematic choices can at least in part be explained by the fact that they fulfil a function, as part of a collectively adopted strategy of the self. Admittedly, the geographical and social homogeneity of thus case study implies that schooling, literacy levels and experiences of writing prior to the war are, broadly speaking, common to the various authors. But no previous intellectual experience had prepared these peasants from Trentino for the task of recounting total war. Yet this they did, and they did it with broadly analogous narrative modalities and thematic priorities. Not one of the 170 authors whose writing I have had the opportunity to analyse tells of having killed with a firearm. Only two admit to having killed in hand-to-hand combat, and reinforce their account of the episode with a series of caveats that I will elucidate below. It is obvious that a shared cultural formation will not by itself account for such a surprising standardisation of the choices the writers make: around the violence inflicted in the first person (and likewise in relation to other themes) there are formed collective narrative strategies which may illuminate the role played by violence within the human group in question.

If writing is a tool, the historian should be able to observe how (with which stylistic ploys and which narrative links) and above all where (on which themes) this tool is used by a community. By establishing what was collectively considered as being worthy of change, it will be possible to identify, on the one hand, some cultural features characterizing the group under scrutiny and, on the other hand, the interaction between the collective self and contingent reality. The silence which so vex the historians cease to be lacunae, and become instead one of a whole gamut of modes in which such a tool can be deployed. The how and the where lead us naturally to ask ourselves why this use occurs - why precisely this tool, why precisely on these themes, or on that typology of events. This why, I believe, holds the key to the meaningfulness of personal writing within the study of the culture of war.

The texts that form the basis of the present paper were produced during or immediately after the war by soldiers coming from Trentino and serving in the Habsburg army. The authors, who only wrote in Italian and had a good level of literacy compared to the Italians from the Kingdom, came mostly from rural areas. In a rural region such as Trentino, where the only major urban areas were the towns of Trent and Rovereto, the specific thematic features as well as the greater linguistic competence characterizing the texts written by the welleducated and those living in the towns constitute a barely significant and easily identifiable exception with respect to the written production found in the region as a whole.

Between 1914 and 1918, 63,000 men aged between 18 and 50 left Trentino [9], a region of around 380,000 inhabitants [10]. Of these, only 1,700 were deployed as officers from the outset, while the strict code of the Austrian army made 
battlefield promotion extremely difficult [11]. All the authors under scrutiny were drafted into the army, which means that they suddenly had to leave the small rural communities that constituted the only social context they had ever known, and, in a matter of weeks, found themselves on the Austrian-Russian front. Although there are quite a few examples of militarized workers who served on the Trentino front, for obvious reasons the Austrian High Command decided not to employ Italian troops on active duty on the Dolomite Front. The majority of the 170 authors selected for this study were deployed between Galicia and Russia. The selected sources include most of the Trentine personal war memoirs preserved at the Archivio della Scrittura Popolare of the Museo Storico del Trentino.

The word "personal" is used here to describe a piece of writing that narrates real events from the point of view of the author and in which both the narration of the author's own actions and, less frequently, his reflections are very rarely interrupted by narrative digressions. As the research advanced, the term revealed itself more and more ambiguous as the presence of an imagined "audience" started to come to the surface: it became apparent that, in spite of the language used or of the fact that the text was only going to be read by the author himself, the presence of the "Other", a real or imagined reader, characterizes "personal" writing, impinging upon both the social and the psychological meaning of the act of writing [12]. However, in this kind of text the other becomes functional to the self, a mechanism which facilitates the narration and at times even enhances it. The will to communicate as well as to share one's experiences with a real person who is able to respond is almost non-existent in Trentine war writing, including epistolography. All the examples of war writing analyzed here can be considered as a form of writing about the self and for the self.

\section{Conceptual Definitions.}

This paper looks at memoir and journal writing. A journal is obviously intended as a form of personal writing characterized by regular writing sessions recorded soon after the occurrence of the events narrated. Instead the term memoir to refers here to a text which, though produced when the experience of the war was not yet over, recounts in a single writing session the events that happened over a time span longer than a single day. This genre allows the author to look back on the events in their totality; memoirs are usually written during a "break" from combat, during convalescence or after the author have been taken prisoner.

What underpins this choice is the similarity between these two genres both on a thematic and on a formal level, especially in relation to the hierarchical order of the events narrated as well as to the cultural and personal significance of this form of plot-construction (emplotment). The transposition of the concept of emplotment - used by Hayden White to define the different levels of conceptualization of historical writing [13] - into the realm of self-writing cannot be effect without taking some precautions. Historical writing and self-writing are essentially different and even opposed to each other at the level of both form and objective. They are nonetheless related by a kind of primordial link, mainly 
through what White identifies as the key nature of historiography and which he defines as "a verbal structure in the form of a narrative prose discourse that purports to be a model, or icon, of past structures and processes in the interest of explaining what they were by representing them" [13, p. 2]. The aim to create a punctual and constant relationship with past events is what connects these two narrative forms and sets them apart from fictional writing. While treating the past in ways that are often antithetical (the historical past constantly needs to be proven and then challenged again, while the events told in a memoir are based on direct experience and thus free from the burden of proof), both forms of writing claim to be founded on real events. Thus, the shift - whether direct or indirect that the act of writing allows from the level of experience to the level of the plot involves a choice: "Unlike the novelist, the historian confronts a veritable chaos of events already constituted, out of which he must choose the elements of the story he would tell. He makes his story by including some events and excluding others, by stressing some and subordinating others. This process of exclusion, stress, and subordination is carried out in the interest of constituting a story of a particular kind. That is to say, he "emplots" his story" [13, p. 6].

The most common form of emplotment in Trentine popular war writing can be defined as "annalistic". The events narrated in the annalistic memoirs are connected to one another only chronologically - apart from the fact that they happened to the same person, i.e. the author. Any explicit reflection on the self is virtually absent: instead of an in-depth analysis of the writer's feelings, of his fears and his innermost emotions, which the modern reader would normally expect to find in a diary, one only notices an attempt to provide a complete record of a daily routine characterized by incessantly repeated actions. In other words, there is a clear intent to be thorough with respect to carefully selected categories of events marked by simple binary concepts (good/bad; plentiful/scarce) as well as by a disconcerting recurrence of certain themes both in the same text and in various texts by different authors. Topics such as food, working in the trenches, travelling, the daily weather conditions, constitute the main - and sometimes the only - subject matter through which the individual experience of the war is narrated. Once the author decides which details are essential for characterizing a specific event, these are accurately told without variations each time the same event arises. As to those facts that are unique such as a battle, the death of a friend, a period of leave -, they are reported with special caution and through a series of rhetorical strategies that will be analyzed later on in the article.

Resorting once again to Hayden White's terminology, it is possible to identify a different and more unusual way of narrating the experience of the war. "Chronicles are, strictly speaking, open-ended. In principle they have no inaugurations; they simply 'begin' when the chronicler starts recording events. And they have no culminations or resolutions; they can go on indefinitely. [...] In the chronicle, this event is simply 'there' as an element of a series; it does not "function" as a story element" [13, pp. 6-7]. This sub-genre is mainly popular among those soldiers who possess stronger writing skills and concerns texts written after the war and characterized by a widespread use of the retrospective gaze (autobiographical memoirs). Despite being strictly chronological, the narrative structure of a chronicle is not exclusively based on the repetition of the same recurring facts, but is sustained by a series of self-contained episodes in 
which the author is the main character. Here, one does not find the same attempt to give an exhaustive account as in annalistic writing, where every single coffee drunk in the trenches must be accounted for. Instead, a demonstrative intention comes clearly to the surface: the main agent's actions, which often reflect his struggle to escape from the war or to make it more bearable, are usually there to prove his cleverness or his resistance to the requirements of military life. In both genres any possibility of personal transformation involving the main character is totally disregarded.

While in annalistic writing the experience of the war is narrated by a protagonist-witness who has no control over the events he is forced to endure, chronicles are centered on a protagonist-actor who plays an active role in the war and who, to a certain extent, makes conscious decisions to alter its course. There are two main reasons why this study has chosen to focus only on annalistic writing. Firstly, this is the most common form of emplotment used during the course of the conflict. This is undoubtedly the means through which the Trentine peasant class, which constituted the large majority of the region's population, chose to record its experience of the Great War. Secondly, even those who tried their hand at more complex forms of account (memorials and autobiographical memoirs) often drew from an annalistic text written shortly after the occurrence of the events. Even when it is not possible to compare the source text with the one based on it, the presence in the chronicles of elements typical of annalistic writing (the exact time of a meal, the number of fellow townsmen one met on a specific day), as well as the seeming "uselessness" of some of them in those texts that aim to recount a long and exceptional period of time, says a lot about the fact that annalistic writing is the source from which popular writing draws both its main themes and the manner in which the author structures his own memories [14, p. 74].

\section{Annalistic memoirs}

In commenting on the Annals of Saint Gall [15], Hayden White states that the chronological chain of years, inasmuch as they are years "of the Lord", constitutes the framework of the emplotment. Consequently, the structure of Medieval Annals is to be found in chronological succession, a continuous line even when nothing is said about a specific year - running between the inaugural theme of Creation and the conclusive event of the Final Judgement. War "annals" from the Trentino front clearly possess different features, primarily due to the personal character of the texts, which, while aiming to be objective, narrate the events only from a personal perspective rather than according to the divine perspective of the "years of the Lord".

However, annalistic memoirs also stand between two founding events: the moment of departure and that of return. The war thus comes to constitute a period of time constrained in a chronological interval that forcefully takes the place of traditional time. It is interesting to note that there is a marked dissonance between the attention devoted to the description of the founding event and the narration of the conclusive one. While a clear effort is made to characterize the departure by means of a lofty and somber narrative key, the 
event of the return is often dismissed with a few sentences that simply announce the end of the war experience. Of course, such a difference cannot be explained in terms of a greater or smaller emotional connection, but is rather linked to the relationship mentioned earlier between the act of writing and the experience of the war, as well as to the fact that the former is mainly dependent on the latter.

Though little attention is devoted to the theme of homecoming, this does not diminish its importance with respect to the conflict as a whole. On the contrary, all the memoirs from Trentino - especially those belonging to the annalistic genre, as well as the complete epistolography, can be thematically defined as literature of homecoming. Both in the journals and in the letters, the moment of reunion with friends and family is evoked, described, and at times even narrated as a real event: envisaging a future of peace is one of the most common motifs of war writing. The remembered past and the imagined future share the same features. Remembering peaceful times is synonymous with imagining a peaceful future; only the abnormality of the present, and not the reality that awaits them when such a state of abnormality is over, seems to worry the conscripts. The description of the return is therefore not useful within the more general scope of the narrative. The image with which the reader is left at the end of the text is that of the author who naturally shifts back into his old timeframe, becoming easily reintegrated into the family structure he had left.

Within these chronological limits, each annalistic piece of writing recounts the war through a series of fixed themes that recur in the daily entries of the journals as well as in the memoirs. The number of these themes is relatively limited, while each one of them is linked to a daily activity or to a cyclic event: working, receiving the mail, the weather conditions, eating, heavy artillery fire, being transferred. Each of these themes - which often overlap or alternate as the author's personal situation changes - can be characterized either positively or negatively depending on the context. Working can be heavy or light, the weather good or bad, rainy or torrid, food plentiful or, more often, scarce, artillery fire can be intense or "calm", travelling can be difficult or, more rarely, easy. As regards the correspondence, it tends to contain more information, including the number of letters sent and received as well as the names of both senders and addressees. In the more complex texts - particularly in the memoirs - the narration of those events which cannot be easily inserted into the given structure develops around these recurring themes. This is what happens both in the case of exceptional manifestations of the above-mentioned phenomena which need a more extensive description, and in the presence of unique and rare situations.

The following is a whole page written by a conscript called Giovanni Zuliani. We know little about him, especially due to the hermetic nature of his journal. He was born in Soraga (Val di Fassa) and probably worked as a farmhand, as seems apparent from the duties he says he carried out at the service of a bacan (a wealthy farmer), even though this activity might be linked to the necessities of war.

5-4 all day Agram until 9pm. / Arrived at Brot 7am / 6-4 left Brot 2pm 16-4 / arrived at Doboi 9:30pm 16-4 / 22-4 one hour break for a meal / 10am Saturday 4-5 Saturday got the train nice weather at 12 o'clock at night arrived at Brot / stopped there until 9am / arrive at Iagreb 8pm / depart at 9am / I am in Stainbruch at 10am / arrive at Laibach at 6/depart at 7/ at 10 I arrived at 
Assling and changed train / 6-5 arrive at Willach at 12 o'clock at night / at 1 o'clock to Fransesfest I arrive there at 9 / 7-5 arrive at Ora at 8 [?] rain / 22-6 fled from home arrived at $S$. Martin then rain went straight to Predazo.[Here and in the following citations spelling mistakes and incongruous punctuation have been corrected in the English translation, while sentence structure has been left as in the original whenever possible.]

This passage seems to bear little significance for the historian, as it can only be useful for reconstructing the journey of a single soldier from the front to his home country between April and June 1918. In order to get more out of it, it is necessary to analyze it within the more general context of the journal as well as in the light of other examples of war writing from the same period.

The regulating principle of the passage quoted above - as well as of the diary as a whole - clearly consists in the author's constant physical dislocation. What emerges is a strong intention to be precise and exhaustive as regards the main narrative theme, even going as far as specifying the exact time when certain actions were performed. During leave - Zuliani's health state was weak due to a leg injury as we learn from the diary, the accuracy of the narrative flow is interrupted. While before even the time of a meal seemed important, the period of leave produces a chronological vacuum that lasts one month and a half, until the author "flees home", by which he means that he "leaves home".

The author, whose name never appears in the text, is basically the only character. Apart from him, the only human beings that are (rarely) included in the narration are some friends and family members. They are only mentioned when the author meets them personally, while the entries simply attest to the encounters rather than celebrating or explaining them. The only event that happens outside the author's personal visual field is the death of Emperor Franz Joseph; even in this case, however, the event is told by means of the same narrative patterns used many times before to give account of transportation, the weather or food:

\section{XI [19]16 Wednesday 2 o'clock our Emperor has died}

The events that involve the author's personal sphere of action are also subject to a similar treatment. When they are not completely omitted their inclusion, normalized through the annalistic structure, is intermittent. Here's how Zuliani talks about the front line:

31-12-17 moved to the line of fire Monday cloudy cold Tuesday New Year in the line of fire stayed there until 1-2 river Putna is 20 feet away from the tequm [from the German Deckung: trench] the Seret is 400 feet further on the village before the line of fire is $\frac{1}{2}$ kilometer from us [?] the Putna and the Seret is called Calieni 8-1-17 warm like September day 10-1-18 there is one inch of snow Thursday 13-1-18 went to the Captain on Sunday to apply for leave

Weather conditions, place, date. Nothing, apart from the fact that the depiction of the two rivers is the most extensive description to be found in the notes, tells us whether the month spent at the front has changed the author's perspective or deserves further attention. Instead we find a temporal gap, with a hint to the fact that the author is in charge of transporting ammunition, which 
ends when Zuliani applies for leave. From his notes, he appears as a very selective observer rather than as an active participant in the war. The surgery he underwent is treated in an equally "normalized" and concise manner: "26-3-17 Thursday 9am they made a cut in my leg". On one single occasion is the rigid cage of writing broken in order to let the author's emotions emerge. This happens when he resorts to self-exhortation and the dialogue with God, which are usually typical of more complex forms of account:

It's going well, come on. On the morning of 31-7 worked until midday then faerum [from the German Vergatterung: muster] Let's go [on?] what do you reckon, Lord, I will be ok won't I?

If this rigid mask only characterized the more basic texts written by the less attentive authors, by those with a poor level of education, or perhaps by those who experienced the war from an unusual perspective (as in the case of Zuliani, who was frequently granted special leave probably due to his leg injury), it would not be so significant. What is surprising is that a similar thematic rigidity can also be found in those authors with no obvious linguistic problems and who were not spared any of the atrocities of war. Let us consider the example of food, one of the main topics that make up the structure of annalistic memoirs:

26.4.17 and 27.4 Arrived at Rava-Ruskaja and got some food; I thought about my fellow-townsman Cesare; in the evening I left for the Volinia region and in Socal I got off the train and had some coffee and bread. During the night I left for Rzeszow where I arrived at 3am; here got off the train and drank some coffe .. ... and then got on the ferbande [from the German Feldbahn: military train] arrived near the bridge and had some preserves and coffee and sauerkraut and then, in the evening, went to sleep in the barracks(Journal of Teodoro Ceschi)

It is clear from this passage that the author's intention to remember is extremely weak: the information recorded in the diary is ancillary with respect to what actually happened. The reference to the fact that he was constantly moving around is probably easier to understand, but the fact that the various destinations - rather than the personal experience of the journey - and the food are basically the only details of the war to which Teodoro Ceschi devotes his attention is undoubtedly quite surprising. Ceschi seems to be much more at ease in his role of narrator than Zuliani; his grammar is usually correct and he is much more prone to digressions that challenge the structure of annalistic writing. Quite surprisingly, however, the central themes are essentially the same. The fact that one feels free to make digressions, which are balanced by moments of impenetrable silence, does not mean that one bypasses the regulating principle that governs writing and memory or that such principle is not based on the themes that are common to the Trentine group as a whole.

In the already mentioned essay "The Value of Narrativity in the Representation of Reality", Hayden White stresses the fact that every form of annalistic writing - defined as a list of bare facts with very little narrativization which are linked to one another only chronologically - often arouses surprise in the modern reader due to the seemingly naïve attitude of the compiler, who does not transform events into a narrative. A similar reaction of surprise is also caused 
by the reading of most Trentine war diaries: how can someone who experienced a war and other violent manifestations of modernity for the first time find no other words to describe such unique events and sensations? How can there be no effort, no matter how successful, in this direction? How can one make sense of the fact that when he gets injured for the first time, after making a list of the various places he called at and of the letters he received, the author does not feel the urge to change the narrative key and describe the context in which the event took place, choosing instead to simply state a fact as if he were talking about his daily meals?

Food was a key aspect of daily life in the trenches, due to both its scarcity and its poor quality. Its regular presence in the memoirs is obviously a further proof of the fact that both the Austrian soldiers and the war prisoners in Russia were in a state of deep malnutrition. It is easy to imagine that food was a regular topic of conversation in the trenches. It was often the object of active searches, either by asking family members or through a variety of expedients and acts of insubordination, which, however minor, involved a serious risk of punishment. Around the topic of food one perceives the creation of forms of sociability that are only rarely narrated and which, through the preparation of a typical dish using whatever ingredients available, reinforced one's memories and helped to close ranks. If more rations were distributed one could also guess how many men a certain battalion had lost the previous day. Moreover, food is also an important indicator of the difference between the group of soldiers from Trentino and the German-speaking troops as testified by some of the chronicles, while it also clearly shows the self-perceived superiority of the Trentines with respect to the Austrians. However, despite this multiplicity of meanings, in the annalistic memoirs food is usually only mentioned: sometimes it is defined as either scarce or plentiful, good or bad, but it is hardly ever consciously used as a symbol of recognition or as an indicator of the course of the war.

In the extreme conditions of life in the trenches, during the marches, when fighting in the mountains, the weather was as crucial as it used to be on the farm, but for different reasons. The heavy rainfalls that transformed the trenches in mudholes turning a shelter into a trap were as significant for those who fought in Russia and Galicia as were the snow and the heavy winter for the troops deployed on the Dolomite front.

The importance of being constantly on the move in the experience of the Eastern front, which was much more dynamic than the Western one, is clearly evident. From the perspective of a rural worker who had usually traveled very little, the considerable number of places visited was certainly the primary sign of a disconcerting change. Poor transportation conditions, the harshness of the marches, together with a lack of explanation about the aim of the journeys and a total ignorance about the overall itinerary, were some of the main causes of malcontent and alienation, which certainly fuelled discussions and speculations. On the other hand, this opens up further questions: if we assume that the novelty of the places visited was disconcerting, that discussions were frequent and that the proximity to the front line was crucial in relation to one's living conditions, why would one simply make a detailed list of all the places where one stopped instead of developing a narrative around the most significant ones?

The same can be said about work duties. It is true that in the trenches one hardly ever engaged in physical battle, nor was one constantly under fire or 
involved in violent episodes. The fact that doing physical work (such as digging, gathering food or building something), being on guard duty and training were quantitatively the most significant elements of life at the front, serves as a first explanation as to why they play such a central role in annalistic writing. One cannot certainly go so far as to suggest that these authors had become so used or even indifferent - to their new living conditions that the fighting, the bloodshed, physical pain, sexual frustration and even death became accessory both rhetorically and qualitatively. Such a statement would not only defy common sense, but it would also contradict the fact that our authors described the event of the war as an immense catastrophe and in terms of divine punishment. So, in order to find a plausible explanation for this phenomenon one should take into account the formal structure of the texts rather than focusing on the reality of lived experience.

Annalistic writing conveys reality through the transposition of its most frequently recurring elements. Emphasis is achieved through the number of entries regarding a particular event rather than through the quality of rhetorical construction. What connects events is their chronological succession, which follows a self-referential order and which regularly refers to a time scale created outside of the context of the war, that of the religious festivities held in times of peace. Peasant war writing in most cases does not aim at a hierarchical selection of facts that goes beyond criteria of exclusion/inclusion. Once a topic has been included in the narrative, for instance food, it will be accounted for in all its possible manifestations in the daily life of the protagonist, regardless of its relevance in relation to a particular message. In some cases, one finds a clear attempt at accuracy and exhaustiveness, which even leads the author to go back and fill a gap in the chronological order of the narrative:

Last night (I almost forgot) we received three preserves and some dried bread which we were not allowed to eat it until we got permission from our superiors; had $\frac{1}{4}$ of wine (Journal of Fiorenzo Ceschi)

Even though most of the times it does not carry the burden of proof, popular writing is characterized by a kind of "objectifying vocation" in spite of the fact that it moves from a localized perspective with a focus on the physical - rather than on the intimate - life of the protagonist. It is still his own point of view that the author records on paper about what he himself perceives. Yet, as with a camera shot, the faithful framing of events is no guarantee of either faithfulness to reality or exhaustiveness. The eye can exclude as well as include, minimize as well as emphasize. In this collective trick of light and shadow, one can identify some of the tendencies that writing imposes upon lived experience in relation to the event of the war.

Firstly, it is possible to identify a "regulating function" of writing. When talking about an experience that cannot be signified by words, which cannot be explained on the basis of the traditional cause-effect relation and which is separate, both when it is perceived and when it is narrated, from what happens before and after, the conscript often chooses to cling on to those facts that are more easily and more frequently witnessed, and which neither need to be explained nor involve any kind of moral implications. They are simply facts that take place every day. Annalistic style provides a support for the processing of 
memories through writing by giving it a shape that allows it to unfold beyond those specific events which would otherwise require a stronger - and perhaps impossible - communicative and interpretive effort. This support favours both the description - allowing to overcome the problem of how one should recount those events that are hard to put down in words or which are incomparable with any previous experience - and the location of the event within one's life experience. There is no reason why Young's statement about writing the history of the Holocaust should not be applicable to self-writing as a whole: "[f]or once written, events assume the mantle of coherence that narrative necessarily imposes on them, and the trauma of their unassimilability is relieved" [16].

According to sociologist Paolo Jedlowski, "human beings did not always store memories in the same way [...] since each culture defines a specific context in which an individual's modes of behaviour find expression, it seems plausible that the ways in which one approaches memory are also different in different cultures" [17]. Jedlowski even goes as far as identifying a specifically modern form of memory, characterized by an idea of incessant change, by the birth of modern historical knowledge and by the progressive loss of faith in the authority of tradition. If modern memory consists in the perception of change and in the awareness of its inevitability, the perception of both time and its speed will become central to it, and will be felt with unprecedented intensity. It is precisely in the period of the First World War when Jedlowski locates the traumatic moment in which great masses of people sensed a cleavage in the continuity of social time. At that moment, the "traditional" categories of memoryclashed with something that resisted their categorizing and regulating power. Interestingly enough, by drawing on Walter Benjamin's Angelus Novus, Jedlowski expresses this impasse in terms of narrative difficulty: "We know why those who came back from the front were "dumbstruck". [...] What they had experienced could not be told, nor understood, through the language of the culture that was available. The crisis of continuity becomes in this case a crisis of the very faculty of narrating and exchanging experience. In order for an event to be communicated it is not enough that different people experience it in similar ways. It needs to be collectively appropriated; it needs to find the right words to be told within a specific culture" [17, p. 48].

So, two types of temporal experience clashed at the front: the "traditional" type, in which the past explains the present, becoming its mirror-image and its interpretative key, and the "modern" type, which in the turmoil of incessant change leaves the past behind in favour of a unique and, as a consequence, unpredictable future. The war exercises its strongest disruptive influence over the ways in which a community conceives of time [18].

There is, however, a small inaccuracy in Jedlowski's analysis that he inherits from Benjamin. While all survivors experienced a narrative crisis due to their perception of the discontinuity of the war, not all of them took shelter in total silence, even as the experience was still unfolding. It is hard to tell whether the "traditional" conceptual tools available to those who decided to talk about it were perceived as being inadequate, as was certainly the case with the linguisticexpressive tools. What is clear, however, is that in this specific case the words used to narrate the experience had been accepted and used by the community before the war. The authority of the past, with its power to explain the present, is not being questioned; what happens is exactly the opposite: it is the present 
that, due to its resistance to adapt to the accepted categories, is defined as wrong, inaccurate and - luckily - only provisional.

The fact that writing has a regulating power is precisely due to its capability to express in traditional terms something that is not at all traditional. As a response to the disruption of the value system caused by the war, a "cyclical" temporal principle is chosen by which events are both recurrent and highly predictable. This is not simply a case where "old" leftover categories inevitably dissolve by coming into contact with modernity; what takes place is rather an active and collective defense of such categories against the kind of modernity represented by the war. The fact that the war is told according to a cyclical conception of time does not mean that its intrinsic uniqueness is ignored, nor that those who came back actually succeeded in bringing back the world of tradition after an interruption within the cyclical structure of time. The act of giving continuity to a discontinuous experience by locating it within a traditional timescale through language should be seen as an active component of writing, as one of those rare moments in which the soldiers had some control over what was happening thanks to the possibility of narrating it according to their own categories and contingent priorities.

\section{Annalistic memoirs and the self: the reparatory function of writing.}

The regulating power of writing in relation to the perception of traditional time does not fully explain why the annalistic form is at the basis of the processing of memory, especially recent memory. To state that each society has its own ways of acquiring, selecting and transposing memories, and that these are connected to a society's vision of the flow of time, or that in Trentine rural society the transposition of memories within cyclical time appears to prevail, does not imply that Trentine soldiers were blind or indifferent to all the extraordinary (non-cyclical) events the war offered them in their monotonous daily life at the front. The fact that any unusual details enter the narrative stealthily rather than being at its center should therefore be explained as a choice on the part of the authors. I will attempt to reconstruct their motives moving from the effects of their narrative choices on the general economy of their works.

The relevance given to cyclical events also causes the gaps to be cyclical: the creation of an "inclusive light" inevitably engenders "exclusive shadows". In the very act of obsessively repeating seemingly unimportant details, annalistic writing fulfills the function of pushing aside or eliminating some elements of the war experience that are thought to be potentially dangerous for one's selfperception or for the perception of what is socially right or appropriate. Writing has a concealing power. Recording a memory inevitably involves choosing from a wider selection of events; the structure delineated so far seems to be a rigid though not always inescapable - cultural and collective yardstick for this kind of choice. The "mask of the text", constituted by the annalistic structure, is superimposed on the events experienced helping identify which ones can be expressed through a narrative form and which ones require special precautions and interpolations. One should not be surprised if this complex trick of light and 
shadow does not highlight the details that one expects to see. In many cases, "highlighting" the repeated meals, the forced marches or the work duties in the trenches serves precisely the function of creating shadows that become increasingly dark as the light gets shinier. They help to push right to the edge of conscience, and beyond the boundaries of writing, those aspects of lived experience that could have threatened not only the stability of the self but also the conviction necessary to each human being that his or her own categories are adequate to explain the world around them [19].

Once we accept the regulating and concealing function of the annalistic form of emplotment, we still need to ask whether it can, after all, carry a message. The question is what a rigid and formalized structure based on a pre-existing time pattern can tell us about the conflict as lived experience, if we move from the assumption that it aims to hide rather than to communicate the alienating character of that experience. Let us start from an obvious fact. Writing, however descriptive it might be, is neither objective nor merely informative. The possible deviations from the main structure are numerous; in some cases, diverging from the classic register can imply that a particular occurrence is more important than others, disrupting the expected succession of events: Classic examples of such deviations include: prayers, exclamations and outbursts of rage, self-exhortations, or suddenly addressing an imagined recipient. Among all the standardized entries the narration of a particular event stands out forcing one to raise questions. This is true especially if the implications of the deviating event fail to be immediately clear to the reader. The twilight zone between what is incessantly repeated and what is constantly silenced is perhaps the most interesting aspect of popular writing. Moreover, there can be no doubt about the fact that, even in the basic form of annalistic emplotment, information on the weather, food or accommodation is included with the explicit aim to spread the message that the war is inhuman and that the writer is suffering. When it comes to food, for instance, language is clearly never encomiastic: its obsessive presence is an indicator of the fact that food was scarce, while few adjectives are enough to attribute responsibilities and to make both malnutrition and the arbitrariness of food distribution a distinctive mark of the experience of the war. The tendency to describe and repeat does not exclude an intention to characterize the war according to one's personal vision in an explicit manner, at least as the details that one has decided to narrate are concerned.

On the historiographical level, what is interesting to notice is not the fact that the soldiers were actually hungry or desperate, or that the war was inhumane - no such long discussion is needed to prove it -, but that this kind of writing tends to create a representation of the self based on certain acts with the exclusion of others. What meaning could the adoption of the annalistic form have for the author-recipient of the text? Firstly, the thematic choice is not limited to the dichotomy unique facts/recurring facts, but it involves specific recurring facts. The repeated occurrence of a certain event is not enough to guarantee its inclusion in the text - not everything "cyclical" can be part of regulatory writing. At least during the time spent at the front, for instance, seeing wounded soldiers and dead bodies must have been a daily routine; in some cases, which are scarcely documented, the sight of heaps of dead bodies must have been an integral part of the landscape. It is interesting to notice the casualness with which the daily presence of death and the habit of experiencing it are described 
in this unique document by Eugenio Mich. Mich, a farmer from Tesero, gave this testimony only as late as 1989, in an authobiographical memoir clearly developed from a journal or from a personal notebook:

On 28, 29, 30, 31, 1 and on 2 June one could see nothing but men dying, the wounded fleeing and reinforcements arriving. The dead were heaped up against the beech trees and many of them were used to mark trails. One day various journalists and officers arrived who, after seeing all those stinky dead bodies corrupted by the heat and noticing that fluids were coming out of the heaps, reported the situation to the High Command: the order came to bury them (Autobiographical memoir of Eugenio Mich)

Considering that death was a daily experience, linked to the intensity of the bombardments as well as to the frequency and the violence of the attacks, the number of dead or wounded soldiers could have been easily included in the dichotomic structure (many/few) that constitutes the daily fluctuation of annalistic accounts. In spite of this, and despite the fact that both the dead and the wounded are often mentioned in annal-like memoirs, their presence is not frequent enough for it to be considered as a framework both for writing and for conceptualizing time.

Narrating something that is shocking, terrifying or unexptected, or whose implications are fundamental for the future (like the death of a friend, the baptism of fire, getting wounded or being taken prisoner) in the same "neutral" way as one makes a note of each time he drank coffee or piled up wood is in fact anything but neutral. This rhetorical tool shows a further function of writing, ie that of neutralizing on a psychological level through stylistic normalization those aspects that cannot be omitted, but which cannot be understood in their actual personal implications. Writing gives one the luxury to create a hierarchical structure that is not based either on the meaningfulness of the facts contained within the realm of experience or on the power and the number of their consequences over the course one's life, but which is instead inversely proportional to the perceived threat that they constitute. If each one of the journal entries has the same weight, only the quantity of similar entries will create meaning; if each entry is characterized by the same style, even the most excruciating experiences will be counted among the "normal" facts that can be easily communicated. In the Memoria di quera 1918 (1918 War Memoir) by Battista Caliari, the death of two fellowsoldiers and the wounding of two others is swallowed up by a myriad of facts artificially placed on the same level and expressed by means of the same register:

I left Ringia and headed for the stello [from the German Stellung: station] / 4/12 up here on Mount Nozolo there is a something like a small village, with big stone huts and the officers' station with a library and beautiful caves and a beautiful stello all hollowed out with long tunnels and [trenches?] with holes, from which I can see the Ledro valley and the village of Tiarno and Castel Condino and all the heights of Balino and Mount Oro etc. .. ten minutes from the funicular one can see Roncone, Fontane, Lerdaro, Daone, Praso, etc.; every 4 days we have to make this journey to collect wood, every 24 hours we must do a 5-hour on-site work shift; on the 26th I went on leave to get some food to eat 
here, only a preserve and a quarter of bread; 17/2 in the evening my comrades went out on patrol two were wounded, one of whom seriously, the others killed. 11/3 I went home again to get some food to bring back here (hardly any); Italian artillery is firing hard. On 16 May I left for Bondo with the other South Tyroleans, there were 76 of us in total. After two days in Bondo 15 men left for Pinzolo, the rest went back to their battalions

In the deformative and concealing power of writing one can identify the primarily therapeutic function of self-writing. Psychoanalyst Stefano Ferrari talks about the "work of writing" (the self in a traumatic context) in the same terms as Freud talks about the "work of mourning" linking it closely with the "work of memory". While the work of writing "breaks down, dissects and scrutinizes the incoherent flow of sorrow, which is unbearable in its very continuity, preparing it to be processed", the work of memory, which is at the basis of the process of objectification favored by writing, "becomes a truly effective defense mechanism, which not only wipes out but above all changes our past by reinventing whole parts of it. [...] In other words, desire corrects the past by means of retrospective fantasies. Next to screen memories, one could talk about a sort of screening of memory, a kind of mask that controls our desires and fulfills them by projecting them into the past". This work is not possible without either the connection between past and present or the perception that the categories we have for explaining the past are inadequate for understanding the present. This kind of awareness can be reached, thanks to the (regulating) power of writing to transpose uncommon events into a common style: without a general coherence no choice could be made, whether of inclusion, exclusion or distortion. As Ferrari also states, narrative style is not only a particular form of account but "a constant and persistent way of seeing and interpreting reality, i.e. an authentic and permanent strategy of defense of the Self aimed at controlling the innumerable internal and external dangers that constantly threaten it [20].

If the writing of memory is the fulfillment of an urge projected onto one's past, what urge can one find in popular writing? The answer to this question is far from univocal, since it must take into account the specificity of each individual case. However, it is possible to put forward a hypothesis about what kind of urge seems to recur most frequently in the main framework of annalistic writing. All the themes that have been identified as recurrent have something in common that could favour a more profound reading of the issue regarding the message contained in the texts: the author usually has a passive attitude towards the war. We are told about the food being received, the journeys being scheduled, the duties being commanded; in other cases, we are informed about phenomena upon which the author has no control, such as the weather or the intensity of fire, but which he nevertheless has to endure. With the exception of the lists of letters and religious services, all the recurring entries that characterize annalistic writing aim to show the author's reaction of estrangement in relation to the war as well as a lack of individual will characterizing life in the trenches. The war is told through the occurrences that involve the author and which make him act, rather than through the actions he decides to perform against the backdrop of the war. The reader of annalistic memoirs is confronted with a text in which the main character is firstly a spectator and a witness of the absurdity of the war and then also its victim and its puppet. 
In describing himself as an object rather than as a subject of the war, the narrator is making a statement primarily for himself and about himself. This is a first step in the reparatory process: he does not contribute to the chaos in which he finds himself; he is only a victim without any responsibility. Having been abducted from his home and his duties, he does not define himself according to the categories created by the war, but on the grounds of both what he has been deprived of and what has been imposed upon him. This is what the reparatory power of writing consists in, leaving aside the usefulness of silence or deformation. Writing allows the individual to reinvent and reaffirm his own self in the traumatic daily experience of the trenches, reshaping it according to his contingent priorities or to the categories with which he identifies. Following Ferrari's Freudian analysis, it is precisely in the dichotomy passivity/activity that writing plays its therapeutic role in relation to a traumatic experience such as the war. In the act of writing a dissociation occurs in the subject, a sort of psychic distancing between a passive self, which perceives and endures the traumatic experience, and and active self, which in the "limited space" of the text and of its set of well-known rules (among which we can count both grammar rules and the culturally determined rules of emplotment mentioned earlier) processes and selects according to a hierarchical structure. "What from this perspective takes the form of dissociation, constitutes on a descriptive level the shift from the passive to the active state" [20, p. 105]. Moreover, while this kind of trauma - modern warfare inaugurated on a massive scale in 1914 is often considered as one of the most alienating and unsettling events in human history, it is easy to imagine to what extent a need to react was both pressing and unavoidable, and why so many people started to write in the trenches.

The description of oneself as passive is in itself a very concrete affirmation of activity, since it presupposes a choice on the level of both style and content. The inhibition of both word and action achieved through this kind of disciplining mechanism not only generates a very clear message, but also allows the fulfillment of a well-defined urge: affirming that the writing self has got nothing to do with the war, but that he observes and endures it instead of contributing to its course.

Looking back at the 78 days he spent in the army between 3 August and 21 October 1914, when he was taken prisoner by the Russians, on up to 46 occasions Battista Chiocchetti decides to talk about every time he ate (or fasted), specifying what he had to eat or drink and sometimes even how much and what it tasted like. The rest of his war memoir is mainly devoted to giving information about the journeys, the terrible conditions in which he was forced to sleep and the scenes of violence that he had to witness, always as a mere spectator without any form of personal involvement, not even as a victim. Every single action performed by the protagonist has been cruelly imposed upon him; his individuality - his tastes, his decisions, his dislikings - become inevitably blurred into a general "we" manipulated from the top. In the midst of a forest of terms referring to food, eating or the managio (rations), the verb "to fire" appears only once. It is September 7: "Once again out in the open field, we joined another company and had to entrench because the balls were hailing down on us; we fired back but then had to retreat". On the basis of what we are told in the memorial, this would be the first and only time in almost three months spent at the front that Chiocchetti uses his gun. Even if we assume that this was actually the case, 
it is important to notice that when describing the act of shooting another human being for the first time in his life, the author uses the same style as when he tells us that "after midday we got some managio [from the German Manage: rations] and then went to get some hay for the night". There is no suspense, no stylistic vibrancy, no sudden excitement that might announce an unusual or especially meaningful act, nor is there any attempt to switch register or to highlight the fact.

It is clear that the text has been subject to cuts and interpolations involving only certain aspects of the experience of the war: Chiocchetti had fired his gun before, but thanks to the annalistic structure very little remains in his selfperception of the impression left upon him by this action. What instead is left is an equally interesting awareness of self-repression, of a desire to be silent and of ways of emplotment through which this silence becomes real and justified. The fact that writing has beneficial and even therapeutic properties is widely known both in the pshycological and in the literary fields, so much so that the idea has been widely applied and theorized [21]. It is no coincidence that James Pennebaker, founder of the "writing paradigm" applied to psychotherapy, has also dealt with writing about the concentration camps. In spite of being radically different, this kind of experience is also characterized by an extreme degree of alienation, by the fragmentation and questioning of the Individual Self and by the persistence of the trauma.

The "explosion of writing" that took place during and after the war can be read as a collective and instinctive adoption of a "tool" that could help make the experience of the war mentally endurable, minimizing its fragmentary and absurd nature within "traditional" and culturally determined cognitive structures. The following section analyzes how such a tool was used in a specific case. The instinctual nature of such an attempt inevitably shapes its contours and possibly its outcome. If the therapeutic context requires a direct involvement with the narration of the trauma - as well as with the physical presence of the psychologist - popular war writing seems rather to avoid it, to minimize and even neutralize it, usually preferring an event-based narration to the kind of "expressive writing" that is needed for the therapy to work [22].There are, however, some key advantages linked to the writing practice, in particular the achievement of control over events through the process of plot-construction and the so-called "post-writing process". The latter consists in a prolongation of the processing favoured by the very act of writing after this is over and representing a real "cure of thought" which continues to be effective also in circumstances that are not controlled by a psychotherapist [23].

\section{Narrating violence}

The theme of war violence has been at the centre of a heated debate that has contributed to link it to the issue of the reliability of the sources within the wider context of a cultural studies approach to WWI. Those who view "grassroots" violence as the "core" of the war and as a prism through which one can read every personal experience of the conflict, have been led by the persistent silence of the sources to disregard these testimonies as reticent, partial, unreliable and 
scarcely significant [1]. Other historians have interpreted this reticence as an affirmation of intrinsic refusal towards the violence of the war and as a proof of a pacifist attitude among the conscripted popular classes [5, 24].

The descriptions of the battles in Trentine personal writings usually follow the annalistic structure: the events are narrated in the order in which they are perceived to have occurred. This order is only altered when a number of events are perceived at the same time:

The next morning as I was walking up a hill I saw many corpses laying on the soil of men killed the day before. In the thick woods I also saw bodies of Russian soldiers killed behind the bushes where they had looked for shelter. In the clearing at the edge of the wood the terrifying spectacle of the battle opened up before our eyes! The thundering of cannons and the explosion of bombs merged with the heartbreaking cries of the wounded and the death rattle of the dying. My head was spinning, I could not think nor form any thoughts (Memoir of Fioravante Gottardi)

In the extremely common cases in which this overlapping of events can not be easily described, the author does not select the most significant aspects or those that have made a stronger impression on him but he simply resorts to fixed formulas ("it's impossible to explain", "I couldn't say", "it was like the end of the world", "it was like hell"). Battles cannot be told in their totality, which helps explain why the sources are often reticent about them. When it is not considered to be irresolvable, the problem of the communicative power of narration is solved by means of recurring metaphors, among which, next to the images of the slaughterhouse and "hell", the idea of the natural catastrophe especially the "storm" - is particularly frequent. Machine guns and shrapnel become "hailstones", "lead drops", "thunder" or "snow". "Who can picture with words the hissing sound of the grenades followed by the roar of the explosion?", asks Rodolfo Bolner in his autobiographical memoir. But then he adds: "The earth in front of us is an erupting volcano".

Though this rhetorical tool is obviously not limited to these authors, the most extreme and catastrophic natural events are used to describe the undescribable aspects of the war in order to dislocate violence onto well-known phenomena that make sense from a farmer's point of view. In the words of Cirillo Mazzola, extreme weather conditions merge with the intensity of the artillery fire (a hurricane of cannons) in a description that gives a good sense of both the simultaneity of the events and the challenge posed to the subject's mental stability:

Today, June 27, the entire battalion was off-duty but the cannon kept hissing close to us but we were safe. During the night between 27 and 28 in the evening a storm broke out at the same time as the battle which lasted for the whole night and sounded like a hurricane of cannons and Gevermarsine [from the German Gewehrmaschinen: machine gun] and grenades (Journal of Cirillo Mazzola)

By favouring a transfer of meaning into a context that is familiar to the writer, the use of metaphors in the descriptions of fighting allows to narrate an experience that cannot be contained within the boundaries of either thought or 
writing. This is clearly a "textual strategy" that works as a "mental organizer" thanks to the ability of rhetorical figures to translate what is inconceivable into something that can be communicated and interpreted. Interestingly enough, the use of metaphors has been defined as a logical-rhetorical mechanism that allows semantic contexts that would not naturally meet to intersect one another [25, p. 107].

A particular kind of metaphor, the ironic one, moves from a similar realization of indescribability to a different aim. Hayden White defines irony as a meta-tropological category [13, pp. 36-37], identifying its key figurative strategy in the "catachresis" (literally "misuse"), the manifestly absurd metaphor designed to inspire Ironic second thoughts about the nature of the thing characterized or the inadequacy of the characterization itself". The violence of the conflict is at times subject to this form of denial: ironic metaphors allow to connect two experiential fields which are totally separate and even opposed (like, for instance, a celebration and barrage fire). This implies dropping the vain ambition of producing a description, which is impossible due to both the appearance and the implications of the scene that has been witnessed, in order to decrease the destructive potential of the experience of the battle through the category of the absurd.

By analysing the formulas that are commonly used to describe all the violent or extraordinarily painful aspects of the war, and especially those that involve the author, one cannot but notice the widespread use of ironic metaphors, which have the effect of minimizing the event in the eyes of the writer and which probably reflect the daily jargon used by the soldiers. The constant noise of the artillery, which was a haunting presence in the trenches, is often described as the "music from the band" or "the concert". The flying bullet is called "zio" (uncle) due to its hissing noise, while the bullets are "candies" to "give out to the enemies".

As regards the emplotment of each individual event constituting the battle, the main strategy identified is the unexpectedly skilled use of what is called "narrative lens", sticking to the image of writing as a camera and of the war as a "stage". In the course of an ordinary narration, the lens is always behind the author-protagonist, highlighting his repeated actions; at the same time, it creates a "blind spot" both on the author himself - whom we hardly see involved in his own actions and whose thoughts are rarely examined - and on all those elements that do not have a direct, physical link with the main character. The other soldiers, for instance, are only mentioned when they come into direct contact with the author, while any anecdote that features them as the only characters is rigorously excluded from annalistic texts.

The description of the violence of the battle challenges the unrelenting "closeup" of the main character that is typical of annalistic writing. As mentioned above, in most cases this crisis gets resolved by means of a dry style that becomes equivalent to silence: the scene of the battle is jotted down with hardly any adjectivization and is "normalized" through the stylistic assimilation of less problematic elements. In other cases, an impressive process of rhetorical neutralization is carried out. The hierarchy of the events narrated changes according to recurring strategies. The narrative lens can open up to catch the entire battlefield through what in cinematic terms is called bird's eye view or establishing shot. The quote from Gottardi reproduced above is a clear example. 
We can add a further example taken from the diary of a builder called Giovanni Lorenzetti; in the following passage, the narrating eye moves away from the author for the first time in the diary:

The shouts the moans the cries of the wounded the heavy artillery and cavalry fire some rushing forward some running back men crying the constant explosions of the huge grenades the Russians threw at us in the woods, it actually looked like the end of the world.

This kind of scene is often followed by a long shot, where the author appears in a group of people, like his battalion or his fellowtownsmen. In this way, the responsibility of the violence is attributed to the whole group rather than directly to the writer. The grammatical subject is collective, and so is the responsibility of the violent act; the verb "to fire" hardly ever appears, and when it does it is conjugated in the first person plural:

Jan. 27 big battle two kilometres long [establishing shot]. We destroyed the enemy's front lines, and the snow has turned black due to the great number of dead Russian soldiers.(Journal of Giovanni Lorenzetti)

A third and more common strategy for excluding the subject from the violence of the visual field consists in zooming in on him until the details of the battlefield are left out (Journal di Riccardo Malesardi - extreme close-up).

Over there one could hear the hissing sound of the Russians' balls and of those coming from our side and aiming at the Russians while we [ill.] [...]. Over there I had a small rosary and I kept praying and praying and I recited the Act of Sorrow I didn't know what to do I didn't even know if I was alive I knew that my mates had been hit and I felt completely lost (Memoir of Angelo Raffaelli)

One should not assume, however, that Angelo Raffaeli, the author of this passage, simply remains hidden with a rosary in his hands. Further down in his diary he says:

we were there for two days then the Russians attacked in four of five waves and we fired until we could my shoulder hurt by dint of shooting [long shot]

Yet it seems that the (collective) act of firing or the scenes of violence witnessed in those days do no deserve any further comment. The author prefers to linger on a few minutes spent praying rather than on two whole days of active combat. There is no mention of anyone being hurt or killed, only a reference to the physical effects of shooting on the person who is carrying the gun. It is clear how most of the actions that make up the scene of the battle are purposefully left out not because they are absent or unimportant but because they are problematic in the eyes of the writer. Once the problem is overcome - i.e. when the author runs away, hides, is imprisoned or gets hurt -, the camera moves back towards the subject. It is interesting to note that the act of hiding or escaping is considered to be neither problematic nor controversial, so much so that it allows to resume the close-up or the extreme close-up. The opposite occurs with the 
exercise of violence, in spite of the fact that it was perfectly normal and even necessary in the context of the war.

Even when the author resorts to a close-up in describing an act of violence perpetrated against the enemy, a self-justificatory attitude is apparent which aims to highlight an external coercion to violence, its inevitability and the essential moral innocence of the protagonist. Giuseppe Scarazzini joins in the shooting only to avoid falling asleep: shooting is in this case a strategy to deal with his own officers rather than a response to the Russian threat.

It felt like midnight would never come so I started shooting to avoid falling asleep. When I pulled the trigger the gun shook my whole body and so I didn't fall asleep, because we were warned that those who fell asleep on duty and got found out by an officer would be punished or even executed(Journal of Giuseppe Scarazzini)

Similar episodes, though more elaborate, are told by Alfonso Cazzolli and Emilio Fusari. The former describes his baptism of fire by means of an extreme close-up that captures him as he hides in a hole for one day and one night under the incessant fire of the enemy's batteries. Having been found in his hiding place and threatened by an officer, Cazzolli is finally forced to hurl himself into the fray. What follows is a very rare description of a not so rare practice, that of cutting the barbed wire and attempting to sneak into the enemy's threnches. Cazzolli tells us that his only objective was to surrender, although he is clearly lying since he threw himself under the enemy's fire with his fellow-soldiers firmly holding his gun after cutting the barbed wire. It is impossible that his intentions - presuming they were real in such a dangerous situation - could be rightly interpreted and subsequently met by the Russians. Not surprisingly, he ends up fighting with cold steel:

I didn't want to kill him but I didn't want to die either, I cannot describe the fight, I don't have the courage, after a few seconds I realized I was bleeding from my right hand, my eyes flashed fire, I suddenly became delirious, I took my gun and threw it against the poor devil, I closed my eyes not to see and when I opened them again I saw blood running down his body [...] I didn't have the courage to kill someone who was asking for mercy(Memoir of Alfonso Cazzolli)

The blade "only" made a five-centimeter-deep cut into the enemy's neck, so the Russian soldier is taken prisoner. We are not told what really happened as the dynamics of the fight, especially as regards the detail of the bayonet thrown without looking, are not very plausible. What is certain is that, in order to talk about an action that was after all expected of him and which justified his very presence at the front, the author needs to take a number of precautions: he was forced to attack; he only wanted to give himself up to the enemy; he didn't want to kill his adversary - and indeed he did not - and, finally, when he hit him he was in a frenzy and even had his eyes closed. His bayonet, which sadly landed in the Russian's neck, keeps away both violence and guilt also on a physical level.

Emilio Fusari starts instead with a bird's eye view of the battlefield: 
It looked like a deluge of fire, smoke, noise! shouts, thunders imprecations prayers. We were there until 9 in the morning in that wasted hell [...] As I stood up I felt an undescribable emotion (Autobiographical memoir of Emilio Fusari)

How painful, he adds, having to come out into such a hell, "under all those bullets, among all those cries and moans", fighting unknown people, all at someone else's whim. Like Cazzolli, he takes a close-up also when describing the attack rather than taking shelter in self-examination or in a wide-angle shot. When he is told to throw a grenade into the Russian trench, he is concerned to clarify that

I threw the first one further down, while the second one nearer to the front line, I didn't want to hurt anybody in cold blood, maybe someone good-hearted ... nicer [compared to the officers who had ordered the attack]

During the night some Russian soldiers ventured into the Austrian trench, taking Fusari and some of his Trentine friends by surprise. Both his intentions and the outcome of the fight are similar to Cazzolli's:

[...] I decided to just defend myself; it was dark, but I was so close that I could see my opponent very well. I was pointing my gun, but only for selfdefence: I didn't have the slightest intention to hurt him [...] At the end they surrendered and we took them as prisoners

It is clear that Fusari's calm decision, taken as he finds himself suddenly engaged in a fight with cold steel in the dark and - according to his memoir - for the first time ever, is as unlikely as Cazzolli's fortunate launch. It does not matter what the actual dynamics of the fights were; what matters is that each episode of perpetrated violence requires, in the rare times when it is narrated, a complex apparatus of justifications that minimize the author's active role. When Fusari is forced once again to fight with cold steel, he refines his rhetorical defence and clarifies the meaning of his actions using the same expression as Cazzolli ("I was like crazy") in order to justify his wounding an enemy:

I was like crazy! Poisoned by such a long and ferocious fight. I struck a blow in self-defence, wounding one of my opponents on the leg; the other one dropped the gun and ran away. I felt terrible! But then I thought that I had done it to save my own life and not to defend those who had forced me to come here and fulfill my patriotic duty

What stands out is that both authors, who are among the very few who portray themselves with a gun in their hands, describe episodes of man-to-man combat. As previously mentioned, this study did not even once in the 170 texts it analyzed come across a description of a killing by gunfire perpetrated from the safety of the trench either in response to or during an attack. A process of "deformation" of the facts through the exclusion of an action (firing) that was certainly more frequent than close combat tells us that the latter, in spite of all the necessary precautions, was considered to be easier to talk about and more 
easily justifiable by means of a "your death, my life" kind of logic compared to a coldblooded murder committed from a safe distance.

\section{Conclusion}

The descriptions of violence and of going into battle quoted above bear out Joanna Bourke's claim that"... the very act of narrating changes and shapes the experience. Men really did kill: but from the moment of killing the event entered into the imagination and began to be interpreted, elaborated, restructured" [26].

What, then, are the rules underlying this restructuring? And what do they tell us about the "war culture" of the authors of such texts?

One conclusion is incontrovertible: whilst it is reasonable to suppose that events did not unfold precisely as Fusari and Cazzolli narrated them, we have no cause to doubt the fact that both were clearly resolved to represent themselves as being opposed to a violent reality which they could not help but live.

Any attempt by the historian to treat the sources as proof of pacifism would, however, be totally illegitimate. In these sources the war is seen as a catastrophe that disrupts and subverts the cyclical movement of time. Yet it is viewed as an essentially natural catastrophe against which any kind of moral opposition would clearly be absurd. This level of caution suggests that the acts committed were of such a nature as to place at risk the perpetrators' positive conception of their own selves. This, however, is not enough to make a connection between the silence on violence and its acceptance, or to reject the value of the sources in determining how their authors felt about it.

The adaptation of the authors' cognitive structures to the objective situation of war is reckoned to be by way of a negation of the intrinsic nature of this latter, as expressed through the selective and distorting power of writing. It seems to me that this impulse serves to justify our discarding, in such cases, the "theory of consensus" advanced by the scholars associated with the centre at Péronne. The need to deny the war in all its manifestations, to redeem it from its most distinctivefeatures and to affirm a pre-existent model of behaviour opposed to it, puts into question the applicability of the categories of "defensive patriotism" [27, 28] or of "crusading spirit" [1] to this case study. Distortion of reality should be read as a resource that is first and foremost to be used and consumed by the ones whoare writing: there is no reason to suppose that they do not feel themselves to be, rightly or wrongly, victims of events. The soldiers saw themselves as victims of the war even as they were shooting and killing, but the effective expression of this perceived reality required a rhetorical distortion - just how conscious it is impossible to say - of the reality experienced.

The sense of victimization, the assertion of his own passivity, the claim that violence is something that he undergoes, the transfer of it to other agents, together constitute a negation of the brutalizationof the author and his peers. The creative endeavour of writing is designed to preserve unchanged the rules of rationality and morality which define what, in peacetime, is thinkable and what is not, what is just and what is not. The tie that writing establishes between the peacetime world and that of the trenches undermines the very notion of "war culture", and the assumption that it was forged by war itself rather than by pre- 
existing cognitive structures. Trentine war culture was defined in terms of values that were in opposition to those imposed by the event: it did indeed arise out of the war and its contingencies, but its characteristic forms were determined by the strategies adopted in order to oppose it and, in the last analysis by "peacetime culture". This has potentially destabilizing implications for the concept of "war culture": if the latter was not determined in the first place by a single totalizing event, its analysis should be conducted in the plural and shouldtake into account differences between the various cultures that meet in the trenches. In short, it is no longer a question of "war culture" but of different "war cultures", as Antoine Prost has already argued [29]: all equally altered by the event, certainly, but according to divergent trajectories, determined by cultural differences preexisting the conflict.

This does not mean that every generalisation regarding the huge cultural influence exerted by the Great War is invalid. But our testing of such general characteristics must be applied to medium and small-scale samples, and on the basis of the words of those soldiers who, in statistical terms, were the protagonists, namely, peasants. The well-known cultural homogeneity of the rural class even in different geographical and historical contexts $[30,31,32]$ and the essentially rural composition of the armies in the Great War suggest the usefulness of studies that look at the ways in which the rural class related its own experience of the war as well as at the cultural significance of the narrative tools. The fact that historians complain about the use of such a common "tool" as that of the "silencing" of violence in war writing from any front suggests that at least some of the ideas developed in the present article can be applied beyond this specific case study.

\section{References:}

1. S. Audoin-Rouzeau, A. Becker, 14-18, retrouver la Guerre, Paris, Editions Gallimard, 2003

2. S. Audoin-Rouzeau, 'Extreme violence in combat and wilful blindness', International Social Sciences Journal, 174, (2002), pp. $491-497$

3. S. Audoin-Rouzeau and A. Becker, 'Violence et consentement: "la culture de guerre" du premier conflit mondial', in Pour une histoire culturelle, J. P. Rioux, J. F. Sirinelli, eds., Paris, Seuil, 1994, pp. $251-271$

4. F. Rousseau, Le proces des temoins de la Grande Guerre: l'affaire Norton Cru, Paris, Editions de Seuil, 2003

5. R. Cazals - F. Rousseau, 14-18, Le cri d'une génération, Toulouse, Privat, 2001, p. 49

6. P. H. Hutton, ed., Technologies of the Self: A Seminar With Michel Foucault, University of Massachusetts Press, 1988, p. 18

7. M. Foucault, 'L'écriture de soi', in Corps écrit 5, 1983, pp. 3-23

8. M. Foucault, Histoire de la sexualité, tome 3: Le souci de soi. Gallimard, 1994

9. S. Benvenuti, 'Il reclutamento dei Trentini nell'esercito austro-ungarico', in La prima guerra mondiale e il Trentino, Rovereto, Comprensorio della Val Lagarina, 1980, pp. 555-566

10. C. Grandi, 'Linee di storia demografica della popolazione trentina durante la seconda dominazione asburgica', in Storia del Trentino, L. De Finis, ed., Trento, Editrice Temi, 1996, pp. 473-512

11. I. Deàk, Beyond Nationalism. A Social and Political History of the Habsburg Officer Corps, 1848-1918, Oxford, Oxford University Press, 1990, pp. 190-212

12. C. Capello, Il sé e l'Altro nella scrittura autobiografica, Torino, Bollati Boringhieri, 2001

13. H. White, Metahistory: The Historical Imagination in Nineteenth-Century Europe, Baltimore, London, John Hopkins University Press, 1990

14. A. Wieviorka, The Era of the Witness, Ithaca, Cornell University Press, 2006 
15. H. White, 'The Value of Narrativity in the Representation of Reality', Critical Inquiry, Vol. 7, No. 1, 1980, pp. 5-27

16. J. E. Young, Writing and re-writing the Holocaust. Narrative and the Consequences of Interpretation, Bloomington, Indiana University Press, 1988, p. 16

17. P. Jedlowski, 'Memoria, mutamento sociale, modernità', in La memoria contesa, A. L. Tota, ed., Milano, Franco Angeli, 2001, pp. 40-67

18. J-F. Jagielsjki, 'Modifications et altérations de la perception du temps chez les combattants de la Grande Guerre', in La Grande Guerre: pratiques et experiences, R. Cazals, E. Picard, D. Rolland, eds., Toulouse, Editions Privat, 2005, pp. 205-214

19. C. Geertz, The Interpretation of Cultures, New York, Basic Books, 1977

20. S. Ferrari, Scrittura come riparazione, Roma - Bari, Laterza, 1994

21. S. J. Lepore, J.M. Smyth, eds., The Writing Cure. How Expressive Writing Promotes Health and Emotional Well-Being, Washington, APA, 2002

22. G. M. Gilli, "La scrittura può curare? Il dibattito e le ricerche", in I non colloqui di Alice, Scrittura e psicologia per una formazione dialogica, C. Capello, ed., Milano, Pubblicazioni dell'I.S.U., 2003, pp. 153-182

23. J. W. Pennebaker, Opening Up: The Healing Power of Expressing Emotions, The Guilford Press, 1997; J. W. Pennebaker, 'Writing about emotional experiences as a therapeutic process', Psychological Science, 8, 3, 1997, pp. 162-166

24. F. Rousseau, La guerre censurée: Une histoire des combattants européens de 14-18, Seuil, 2003

25. "Metaphors, metonymies and hyperboles are not simply poetic linguistic forms, but ways of thinking. They constitute the very essence of creative thought [...] their aim is not to enunciate, by means of a specific semantic substitution, something that could also be enunciated without it, but to express a message, a meaning that could be neither found nor transmitted in any other way." - M. Cavallo, J. Scianella, 'Analisi retorica dell'identità', in Il racconto che trasforma, M. Cavallo, ed., Roma, EDUP, 2002, pp. 101-140

26. J. Bourke, An intimate history of killing: face to face killing in twentieth century warfare, New York, Basic Books, 1999

27. J. J. Becker, 1914: comment les Francais sont entrés dans la guerre, Paris, P.F.N.S.P., 1977

28. J. J. Becker, "La fleur au fusil: retour sur un mythe" in Vrai et faux dans la Grande Guerre, C. Prochasson and A. Rasmussen, eds., Paris, La Découverte 2004, pp. 152-165

29. A. Prost, 'Brutalisation des sociétés et brutalisation des combattants', in Les sociétés en guerre 1911 - 1946, Paris, A. Colin, 2003, pp. 99 - 111

30. E. R. Wolf, Peasants, Prentice-Hall, Englewood Cliffs, 1966

31. P. P. Viazzo, Comunità alpine. Ambiente, popolazione, struttura sociale nelle Alpi dal XVI secolo ad oggi, Bologna, Il Mulino, 1990, p. 38

32. P. Barral, Les sociétés rurales du XX siecle, Paris, Armand Colin, 1978, pp. 5 - 6 